\title{
POTENCIALIDADES E DESAFIOS DA EDUCAÇÃO AMBIENTAL EM SANTA TEREZA DO OESTE/PR COMO PROMOTORA DO DESENVOLVIMENTO RURAL SUSTENTÁVEL
}

\author{
Neiva Feuser Capponi ${ }^{1}$ \\ Ceyça Lia Palerosi Borges ${ }^{2}$ \\ Mauri José Schneider ${ }^{3}$ \\ Renata Rocha Gadelha ${ }^{4}$ \\ Adriana Maria de Grandi ${ }^{5}$ \\ Wilson João Zonin ${ }^{6}$
}

CAPPONI, N. F.; BORGES, C. L. P.; SCHNEIDER, M. J.; GADELHA, R. R.; GRANDI, A. M. de.; ZONIN, W. J. Potencialidade e desafios da educação ambiental em Santa Tereza do Oeste/Pr como promotora do desenvolvimento rural sustentável. Revista de Ciências Empresariais da UNIPAR, Umuarama, v. 21, n. 2, p. 217-236, jul./dez. 2020.

RESUMO: A Educação ambiental quando trabalhada dentro da proposta das Leis Federal 9.795/99 e Estadual 17.505/2013, na qual preconiza que esse tema seja transversal em todas as disciplinas, possibilita na formação do sujeito, uma consciência voltada à sustentabilidade na qual suas práticas contemplem e priorizem os aspectos sociais, ambientais e econômicos de maneira igualitária, contribuindo assim para um desenvolvimento sustentável. Diante dessa importância esta pesquisa objetivou compreender como vem sendo trabalhada a

DOI: $10.25110 /$ receu.v21i2.8007

${ }^{1}$ Doutoranda da Universidade Estadual do Oeste do Paraná - UNIOESTE no Programa de PósGraduação em Desenvolvimento Rural Sustentável - PPG_DRS, campus Marechal Cândido Rondon/ PR, Brasil.nfcapponi@hotmail.com

${ }^{2}$ Doutoranda da Universidade Estadual do Oeste do Paraná - UNIOESTE no Programa de PósGraduação em Desenvolvimento Rural Sustentável - PPG_DRS, campus Marechal Cândido Rondon/ PR, Brasil. ceyca.borges@uffs.edu.br

${ }^{3}$ Doutorando da Universidade Estadual do Oeste do Paraná - UNIOESTE no Programa de PósGraduação em Desenvolvimento Rural Sustentável - PPG_DRS, campus Marechal Cândido Rondon/ PR, Brasil.mauribiojs@gmail.com

${ }^{4}$ Doutoranda da Universidade Estadual do Oeste do Paraná - UNIOESTE no Programa de PósGraduação em Desenvolvimento Rural Sustentável - PPG_DRS, campus Marechal Cândido Rondon/ PR, Brasil.regadelha@hotmail.com

${ }^{5}$ Associada da Universidade Estadual do Oeste do Paraná - UNIOESTE, no Programa de PósGraduação em Desenvolvimento Rural Sustentável - PPG_DRS, campus Marechal Cândido Rondon/ PR, Brasil. adrianadegrandi@gmail.com

${ }^{6}$ Associado da Universidade Estadual do Oeste do Paraná - UNIOESTE, no Programa de PósGraduação em Desenvolvimento Rural Sustentável - PPG_DRS, campus Marechal Cândido Rondon/ PR, Brasil.wilsonjoaozonin@gmail.com 
Educação Ambiental em Santa Tereza do Oeste - PR, de maneira que contribua para o desenvolvimento sustentável do município. Por meio do método qualitativo, descritivo de caráter exploratório e utilizando como instrumento de coleta de dados a análise documental, grupo focal e observação assistemática, foi possível observar que, apesar das escolas municipais e estaduais contemplarem em sua proposta pedagógica a educação ambiental, a mesma não está sendo tratada da maneira proposta na legislação. Porém, é notória a sua contribuição para o desenvolvimento do município e na formação cidadã de seus estudantes.

PALAVRAS-CHAVE: Educação Ambiental. Formação Cidadã. Lei Federal 9.795/99. Desenvolvimento Rural Sustentável.

\section{POTENTIALITIES AND CHALLENGES OF ENVIRONMENTAL EDUCATION AS AN INSTIGATOR OF SUSTAINABLE RURAL DEVELOPMENT IN SANTA TEREZA DO OESTE/PR}

ABSTRACT: Environmental education, when addressed within the proposal of Federal Law 9795/99 and State Law 17505/2013, which advocate that this topic be transversal to all disciplines, allows the individuals to raise awareness aimed at sustainability during their formation. These practices contemplate and prioritize social, environmental, and economic aspects in an egalitarian way, thus contributing towards a sustainable development. Given this importance, this research aimed at understanding how the Environmental Education in the city of Santa Tereza do Oeste, state of Paraná. has been addressed in a way that contributes to the sustainable development of the city. Through a qualitative, descriptive method using an exploratory character, and by using documental analysis, focus group, and unsystematic observation as data collection instruments, it was possible to observe that, although the municipal and state schools include environmental education within their pedagogical proposal, the discipline is not being dealt with as established in the legislation. However, its contribution to the development of the city and its citizens is notorious.

KEYWORDS: Environmental Education. Citizenship Formation. Federal Law 9795/99. Sustainable Rural Development.

\section{POTENCIALIDADES Y DESAFIOS DE LA EDUCACIÓN AMBIENTAL EN SANTA TEREZA DO OESTE/PR COMO PROMOTORA DEL DESARROLLO RURAL SOSTENIBLE}

RESUMEN: La educación ambiental, cuando se trabaja dentro de la propuesta de la Ley Federal 9.795/99 y Estadual 17.505/2013, que defiende que ese tema sea transversal en todas las disciplinas, permite en la formación del sujeto, una 
conciencia centrada en la sostenibilidad en la que sus prácticas contemplan y priorizan los aspectos sociales, ambientales y económicos por igual, contribuyendo así al desarrollo sostenible. Dada esta importancia, esta investigación tuvo como objetivo comprender cómo se ha trabajado la Educación Ambiental en Santa Tereza do Oeste - PR, de una manera que contribuya al desarrollo sostenible del municipio. A través del método cualitativo descriptivo de carácter exploratorio y utilizando como instrumento de recolección de datos el análisis documental, el grupo focal y la observación asimétrica, ha sido posible observar que, aunque las escuelas municipales y estatales contemplan en su propuesta pedagógica la educación ambiental, la misma no está siendo tratada como se propone en la legislación. Sin embargo, su contribución al desarrollo del municipio y la formación ciudadana de sus estudiantes es notoria.

PALABRAS CLAVE: Educación Ambiental. Entrenamiento Ciudadano. Ley Federal 9.795/99. Desarrollo Rural Sostenible.

\section{INTRODUÇÃO}

O vocábulo Educação Ambiental transmite o entendimento que as questões voltadas ao meio ambiente possam ser conferidas por meio dos afazeres pedagógicos. O ambiental é trazido para um reconhecimento que se apresenta por leis e resoluções a fomentarem novos entendimentos quanto às questões ambientais e que precisam ser conhecidos por todos os que estão no dia a dia repassando o conhecimento, desde o ensino fundamental até o superior, tornando estes vocábulos diferenciadores no desenvolvimento sustentável das cidades (BRASIL, 2004). Para contribuir com essas argumentações existem normativas que precisam ser conhecidas para alicerçarem estas novas demandas.

A Política Nacional da Educação Ambiental (PNEA) foi instituída a partir da Lei Federal 9.795/1999, tendo o Art. $8^{\circ}$ como fomentador das ações que devem ocorrer na educação escolar e que essas se façam por meio de um corte transversal, ou seja, perpassando todas as disciplinas e em todos os níveis, desde o fundamental ao ensino superior. (BRASIL, 1999). Aproveitando a percepção do Art. 225 da Constituição Federal e da PNEA foi editada a Resolução ${ }^{\circ} 2$ em 15 de junho de 2012, estabelecendo as Diretrizes Curriculares Nacionais para a Educação Ambiental. Mobilizar os atores que conduzem a prática políticopedagógica permite o reconhecimento e a relevância do ensino da Educação Ambiental em todas as modalidades (BRASIL, 1988: 2012).

Alicerçado às normativas dessa lei, o Estado do Paraná publicou em 11 de janeiro de 2013 a Lei 17.505, estabelecendo que por Educação Ambiental, "entende-se os processos contínuos e permanentes de aprendizagem em todos os níveis e modalidades de ensino" (PARANÁ, 2013, p. 1), para que com esse 
conhecimento as pessoas se tornem comprometidas com os cuidados que o meio ambiente requer. Deixando claro, também que a formação deve ser fornecida aos docentes, a fim de que essa aprendizagem seja repassada aos alunos, pois assim esses se tornam fomentadores desses conhecimentos além dos muros das escolas (PARANÁ, 2013, p. 1).

A normatização de leis relacionadas à Educação Ambiental introduz a percepção de que este assunto deve ser trabalhado pelos docentes instigando a transformação das atitudes desde o ensino fundamental (FRÓES; MILANEZI; BOGARIM, 2011). Quanto mais cedo o conhecimento ocorrer, mais coerente serão as mudanças no estilo de vida da humanidade, contribuindo na relação de bem estar entre ser humano e a natureza. $\mathrm{O}$ saber pode intervir nas disputas que produzem os problemas ambientais, favorecendo com que as decisões éticas possam ser influenciadas, minimizando, dessa forma, os conflitos entre homem e o meio ambiente (AHLERT, 2003).

O Art. $8^{\circ}$ da Resolução $2 / 2012$, estabelece que as práticas educativas quando inseridas na dinâmica escolar, devem ocorrer de maneira contínua e permanente, pois a Educação Ambiental tem como contribuição formar cidadãos conhecedores do contexto histórico e sociocultural, estimulando-os à reflexão crítica de que os cuidados com o meio ambiente são possíveis e, que portanto, "a interface entre a natureza, a sociocultura, a produção, o trabalho e o consumo", superem o pensamento ingênuo e naturalista que ainda ocorre na prática pedagógica dentro das instituições de ensino (BRASIL, 2012, p. 2).

Alicerçados por estas questões que estruturam a Educação Ambiental, esta pesquisa teve como objetivo compreender como a Educação Ambiental está sendo trabalhada em Santa Tereza do Oeste - PR, de maneira a contribuir com o desenvolvimento sustentável do município.

A pesquisa foi delimitada à diretoras de escolas municipais e estaduais, tanto do eixo urbano quanto rural, bem como às secretárias da educação e do meio ambiente, para alicerçar a percepção que essas têm em relação ao ensino da Educação Ambiental dentro das escolas que compõem o município.

Justifica-se este estudo, pela necessidade de analisar as práticas que a direção das escolas tem proporcionado junto ao seu corpo docente, para se adequarem às normatizações da Lei Federal 9.795/1999, a Resolução n 2/2012 e a Lei Estadual 17.505/2013. Levando-se em consideração que os princípios da educação, de acordo com as Diretrizes Curriculares Nacionais (DCN) para a Educação Ambiental, envolvem o atendimento de uma educação cidadã, responsável, crítica, participativa, onde cada sujeito aprende com conhecimentos científicos e com o reconhecimento dos saberes tradicionais, possibilitando tomar decisões transformadoras a partir do meio ambiente natural ou construído, no qual as pessoas se inserem (BRASIL, 2012). 
Este artigo está estruturado em quatro seções. $\mathrm{Na}$ introdução contextualiza-se o tema, o objetivo da pesquisa, a delimitação, a justificativa e a estrutura do artigo. Na seção dois apresenta-se a metodologia utilizada para a captação e análise dos dados. A terceira seção foi dedicada para discorrer a análise dos resultados e na quarta seção são apresentadas as considerações finais, levando em consideração, o que conseguiu atender o objetivo desta pesquisa, além das sugestões para futuras pesquisas.

\section{PROCEDIMENTOS METODOLÓGICOS}

Pesquisa de finalidade aplicada, realizada como requisito parcial para as disciplinas Métodos de Pesquisa Interdisciplinares e Participativos e Oficina de Pesquisa, do Programa de Pós-Graduação em Desenvolvimento Rural Sustentável, da Universidade Estadual do Oeste do Paraná (PPGDRS/ UNIOESTE).

A fim de responder ao objetivo proposto, optou-se pelo estudo qualitativo e descritivo a partir de uma abordagem exploratória. A pesquisa qualitativa é descritiva, pois se preocupa em descrever os fenômenos por meio dos significados que o ambiente manifesta. A abordagem exploratória sugere que a pesquisa explore a realidade em estudo, buscando maior conhecimento, Fantinato (2015) enfatiza que pesquisas assim, proporcionam maior familiaridade com o problema, ao torná-lo mais explícito contribuindo na construção de hipóteses.

Esta pesquisa teve como tema central a Educação Ambiental, sendo desenvolvida com três grupos de participantes: gestores do município, diretores das escolas estaduais e diretores das escolas municipais. A pesquisa de campo foi realizada nos dias 25 e 26 de outubro de 2018, no município de Santa Tereza do Oeste/PR, e como técnica de pesquisa, utilizou-se o grupo focal, pela praticidade que a modalidade gera em reunir grupos a fim, centralizando um tema específico a ser debatido entre os participantes. Utilizada em pesquisas na área educacional, os autores Vaughn et al. (1996), sinalizam que a entrevista de grupo focal é uma técnica qualitativa que pode ser usada sozinha ou com técnicas quali-quantitativas, para aprofundar o conhecimento das necessidades do público envolvido.

A primeira sessão aconteceu com as seis diretoras das escolas municipais abrangendo sete categorias de análise para melhor compreender a presença da EA nas instituições pesquisadas, sendo elas: interdisciplinaridade, diversidade, formação continuada, família e comunidade, princípios e valores, projetos da/ na escola e Programa Nacional de Alimentação Escolar (PNAE). A segunda sessão foi realizada com quatro diretoras das escolas estaduais, utilizando-se das mesmas questões estruturadas para as escolas municipais. No terceiro e último 
encontro estiveram presentes as secretárias do meio ambiente e da educação, a representante do conselho municipal do meio ambiente e a advogada (funcionária da secretaria de meio ambiente), na qual foram abordadas questões relacionadas ao Plano Diretor do Município, distribuídas em três categorias de análise relacionadas ao Desenvolvimento Econômico, Política Social e Política do Meio Ambiente. Contudo, devido à delimitação deste artigo, aqui só são abordados os resultados obtidos em relação às entrevistas feitas com as diretoras. Com o consentimento das entrevistadas ocorreu a gravação para posterior transcrição dos dados, utilizando-se a técnica da Análise de Conteúdo.

A busca de documentos constitui-se como uma valiosa técnica de abordagem de dados qualitativos que, segundo Lüdke (1986), tem como objetivo ratificar ou validar as informações que foram obtidas com outras técnicas de coleta, como a entrevista, a observação e o questionário. Nesta pesquisa os documentos investigados foram: o Plano Diretor de Santa Tereza do Oeste, dados do IBGE (2015), Lei $n^{\circ}$ 9.394/96, Lei $n^{\circ}$ 9.795/99 (BRASIL, 1996; 1999) e Normas estaduais para a EA no Sistema Estadual de Ensino do Paraná (PARANÁ, 2013).

Outra técnica utilizada nesta pesquisa foi a da observação assistemática, pois é uma fonte propícia para a construção de hipóteses, permitindo analisar os fatos ou a correlação existente entre eles (MARCONI; LAKATOS, 2017). A observação neste trabalho ocorreu durante a visita nas escolas, onde se pode investigar o ambiente escolar e sua estrutura, a fim de analisar as condições favoráveis ou não, para práticas relacionadas à Educação Ambiental.

A técnica de análise de conteúdo, utilizada nesta pesquisa, envolveu a verificação da técnica de análise das comunicações buscando entender de forma crítica o sentido exposto ou oculto das comunicações. Nessa análise, podese observar o conteúdo das mensagens, linguagens, expressões verbais entre outros; podendo essas serem verbais (orais ou escritas), gestuais e documentais (SEVERINO, 2007). Todas as informações coletadas nesta pesquisa por meio do grupo focal, análise de documentos, e observação, permitiram o alcance do objetivo proposto, contribuindo com informações tanto para o município de Santa Tereza do Oeste - PR como também para outros municípios e para a academia.

\section{RESULTADOS E DISCUSSÃO}

A interdisciplinaridade vai além do mero diálogo entre as disciplinas, ela pressupõe problemas em comum a serem resolvidos a partir de diferentes perspectivas, de diferentes olhares que as diversas disciplinas têm da realidade diária. Tendo em vista que a Educação Ambiental (EA) visa à construção de sujeitos críticos de suas realidades, a partir da identificação e análise dos 
problemas que se enfrenta na atualidade e contexto, a interdisciplinaridade apresenta-se como sendo a melhor forma de se aliar os conhecimentos científicos com a busca de soluções para os problemas concretos que são enfrentados. E, é por isso, que na legislação sobre EA (Leis Federal 9.795/99 e Estadual 17.505/2013), preconiza-se que esse tema seja transversal em todas as disciplinas e não em uma especificamente.

Em relação às escolas municipais, a EA é desenvolvida em uma disciplina única dentro da grade curricular, ocorrendo desde a pré-escola até o ensino fundamental, compreendendo do $1^{\circ}$ ao $5^{\circ}$ ano. Dependendo da organização escolar é um professor, ou mais, que trabalha com a abordagem desse conteúdo. Com base nas informações repassadas pela diretora, na Escola Levino Jorge Weidmann, há três professoras que trabalham com o conteúdo da EA e, que cada uma faz em uma série específica. Ainda com base no detalhamento da diretora, anteriormente, o conteúdo sobre questões ambientais era desenvolvido dentro da disciplina de Ciências, mas em 1997/1998 ele foi transferido para a disciplina de EA, seguindo os parâmetros da Lei Complementar 37/1987 (PARANÁ, 1987).

As diretoras afirmam que existe dificuldade em se trabalhar a interdisciplinaridade, devido ao tempo. Pois, os professores precisam contemplar os conteúdos de suas disciplinas específicas e acabam focando nisso. Contribuindo apenas quando em eventos maiores, como os que são feitos na semana do meio ambiente que geralmente envolve todas as disciplinas. Além disso, a troca anual de professores também é um problema, não permitindo a continuidade de projetos.

Por fim, outros dois limitantes no trabalho com a Educação Ambiental e a interdisciplinaridade são: primeiro, os professores não gostam de assumir essa disciplina, pois não é sua formação; e, segundo, pela falta de continuidade entre os trabalhos/projetos realizados no ensino fundamental com o ensino médio.

Pode-se perceber que a transversalidade prevista para a EA, de acordo com as Leis, em todas as disciplinas, não está sendo atendida pelas escolas municipais de Santa Tereza do Oeste. Pois, atribuem essa discussão a uma disciplina específica, fato que gera outro problema, segundo as entrevistadas, a disciplina de Educação Ambiental é pouco requisitada pelos professores que, em geral, só assumem a mesma em caso de falta de opção, quando não têm outras disciplinas para fecharem sua carga horária.

Quando há uma disciplina específica, para se discutir a EA, o restante dos professores compreende que não é responsabilidade sua trabalhar esse tema. De início, ocorre a desmotivação para que esses se empenhem em refletir sobre como a Educação Ambiental poderia ser vinculada aos conteúdos que ministram, uma vez que essa responsabilidade lhes é retirada. Ou seja, o trabalho com a interdisciplinaridade acaba, também, sendo desmotivado. Por outro lado, como 
nenhum professor é formado em EA, afinal nem mesmo existe uma graduação com esse tema, necessariamente, quando os professores precisam escolher qual disciplina ministrar no ano, tenderão a escolher àquelas em que eles têm formação, ou seja, as que eles já possuem um aprofundamento, pois se sentirão mais seguros de trabalhar com os alunos em sala de aula. Com isso, a disciplina de Educação Ambiental acaba sempre sendo a última opção.

Percebe-se que conceber o trabalho da Educação Ambiental em uma única disciplina, causa desmotivação para ser trabalhada na escola. Se ocorresse a compreensão de que essa discussão é responsabilidade de todos os professores, a perspectiva transformar-se-ia, e a discussão acerca da EA poderia ser fortalecida. Todavia, isso também só ocorreria se esses professores e diretores contassem com formação continuada, apoio e valorização dos governos/órgãos públicos para a realização desses trabalhos e discussões.

Nas Escolas Estaduais a Educação Ambiental é trabalhada de forma transversal em todas as disciplinas. Todavia, de acordo com a diretora da Escola Estadual Santa Tereza, as disciplinas que mais se envolvem com esta temática são: Geografia, História e Ciências, à que ela manifestou:

Quando comentei das disciplinas de Ciências e Geografia, são mais com os trabalhos de horta, os professores [em geral] trabalham os temas interdisciplinares dentro das salas de aula como temas transversais. Existe esse envolvimento do professor, na questão de etnias, meio ambiente, tema de formação multidisciplinar, temas sobre as plantas medicinais, na feira de ciências, houve esse trabalho.

Todavia, é possível perceber que a interdisciplinaridade, nessas escolas, poderia ser melhor aproveitada. A Escola Estadual Santa Tereza desenvolve um projeto com horta e captação de água da chuva. Quando questionado às diretoras se é explorada a potencialidade da diversidade de estudos que podem surgir a partir dessas práticas, tais como: reforçar o olhar ecopedagógico e de sustentabilidade do uso da cisterna, onde com a captação e o reaproveitamento da água para lavar saguões e dar descargas em banheiro, também a utilização para irrigar a horta, onde os professores poderão trabalhar nesse espaço as disciplinas de Matemática (formas geométricas, espaçamentos, metragem, cálculo), ciências (ciclagem natural de nutrientes, decomposição, formação do solo), Geografia (características da superfície do planeta Terra, os fenômenos climáticos e a ação do ser humano no meio ambiente e vice-versa, permitindo ao aluno compreender o ambiente em que vive) as diretoras afirmaram que ainda há dificuldade em se fazer essas conexões. 
Quanto à diversidade, a LDB da Educação Nacional 9.394/96 e os Parâmetros Curriculares Nacionais preconizam a atenção à diversidade da comunidade escolar. Diversidade étnica, cultural, econômica, social, entre outras. Segundo as DCN para a EA (BRASIL, 1996: 2012, p. 4), um dos princípios da Educação Ambiental é "respeito à pluralidade e à diversidade, seja individual, seja coletiva, étnica, racial, social e cultural, disseminando os direitos de existência e permanência e o valor da multiculturalidade e plurietnicidade do país e do desenvolvimento da cidadania planetária". Sendo assim, um dos objetivos da EA é que os currículos enfatizem a natureza como fonte de vida e relacionem a "dimensão ambiental à justiça social, aos direitos humanos, à saúde, ao trabalho, ao consumo, à pluralidade étnica, racial, de gênero, de diversidade sexual, e à superação do racismo e de todas as formas de discriminação e injustiça social" (BRASIL, 2012, p. 4).

Para tanto, dentro da organização curricular, deve-se ter o compromisso "da instituição educacional, o papel socioeducativo, ambiental, artístico, cultural e as questões de gênero, etnia, raça e diversidade que compõem as ações educativas, [...] da Educação Básica e da Educação Superior" (BRASIL, 2012, p. 5).

Nas Escolas Municipais, a questão da diversidade é trabalhada a partir dos conteúdos, com reflexões e observações. As diretoras afirmaram que não é realizada nenhuma discussão em relação à questão de gênero, pois consideram que as crianças são muito novas para este tipo de discussão; quando surge alguma situação em demanda específica, então se trabalha o tema, mas não tem um conteúdo/planejamento para abordar essa discussão.

Em relação à diversidade religiosa, as diretoras consideram importante que seja feita essa discussão, pois existe muita diversidade no município. A disciplina de Ensino Religioso busca abordar as questões quanto à diversidade étnica, cultural e social.

Nas escolas estaduais as diretoras identificaram alguns problemas relacionados com o tema da diversidade: no período da manhã, frequentam os estudantes com maior poder aquisitivo. Os problemas que esses alunos apresentam estão relacionados, na maioria, a questões psicológicas: depressão, mutilação, ideação e tentativas de suicídio. No período da tarde e noite, frequentam os alunos com menor poder aquisitivo, e os problemas que surgem são outros, destacando-se a questão da violência; sua diretora atribui ao fato de muitos estudantes terem pais que já foram ou estão presos, dessa forma, as diferentes violências vivenciadas nas famílias são reproduzidas no ambiente escolar. A maioria das brigas ocorre fora da escola e surge de discussões, sobretudo, geradas em conversas pelo aplicativo WhatsApp, tendo como causa relações amorosas e a falta de controle das emoções dos jovens. Além disso, a 
escola apresenta problemas com o uso de cigarro e consumo de álcool e drogas, já desde o sexto ano do ensino fundamental. Para enfrentar esses problemas tão complexos, a direção da Escola Santa Tereza busca ajuda de profissionais da saúde, da prefeitura, do conselho tutelar e palestras diversas para a conscientização destes temas. Tal como pode ser observado no excerto da diretora: "a escola tem muitas situações de violência, as ideias de suicídio, não é um ou dois, são grupos que descobrimos dentro da escola, por isso as parcerias são fundamentais, pois minimizam e contém esses casos".

Como os problemas dos estudantes são muitos e complexos, as diretoras solicitaram a contratação de mais profissionais, por parte da prefeitura, para auxiliá-las neste trabalho. Sendo contratados mais dois profissionais. Mas para a diretora da Escola Estadual do Campo de Santa Maria, o Estado deveria disponibilizar um psicólogo para cada escola.

Outros dois tipos de diversidade estão presentes e têm sido trabalhados de forma satisfatória, segundo as diretoras: a questão da inclusão de deficientes (mental, visual) melhorou muito, devido às formações com os profissionais e a Lei de Inclusão ${ }^{\circ} 13.146 / 2015$, que permitiu a criação das salas de recurso (BRASIL, 2015). Em relação à homossexualidade, não há preconceito entre os alunos, o que ocorre é o medo de revelar aos familiares.

Um problema prioritário a ser trabalhado, diz respeito aos problemas psicológicos enfrentados pelos estudantes. Esse tema se relaciona com a discussão de princípios e valores. Vive-se uma crise de civilização (LEFF, 2001), uma crise de valores e de sentido. Qual o sentido da vida? Quando um jovem se faz essa pergunta nos dias de hoje, qual será a resposta que ele obtém? Observa-se que a visão liberal e cartesiana que fortaleceu o egoísmo individualizante trouxe problemas não só para a relação com o meio ambiente (levando a sua destruição), mas também a relação entre os seres humanos, bem como na relação consigo mesmo. Qual o sentido em viver em uma sociedade na qual impera a competição e a disputa a todo o momento, na qual a cooperação não é vista, nem valorizada? Uma sociedade que destrói seus próprios meios de sobrevivência? Somado a tudo isso, tem-se uma sociedade que, de tanto individualizar-se, entende que os problemas são individuais e não têm causas sociais. Ou seja, os indivíduos não se compreendem como sujeitos da construção histórica, e não compreendem a construção histórica interferindo na vida deles.

Nesse sentido, a Educação Ambiental poderia contribuir quando se preconiza a construção de sujeitos críticos, que sejam capazes de refletir sobre a sua própria realidade, sobre os problemas que identificam e vivenciam no seu dia a dia, sejam eles no plano micro ou macro. A EA preconiza que se relacionem os problemas ambientais com os sociais, que se "quebrem as caixinhas", que sejam capazes de visualizar o todo. Logo, compreender que não existem partes 
separadas, mas sim, que tudo está interligado. Sendo assim, procura gerar a compreensão de que sozinho se é capaz de muito pouco, mas, quando unidos à capacidade de construir a história, gera-se a possibilidade de sonho conjunto. A Educação Ambiental tem a potencialidade de fazer com que as pessoas voltem a sonhar.

Tornou-se visível a percepção de que as escolas estaduais enfrentam desafios muito sérios no que diz respeito ao trabalho com a diversidade. Essas escolas se mostraram empenhadas na busca de soluções para os problemas apresentados, todavia, constatou-se a necessidade de que os órgãos públicos (prefeitura e governo estadual) deem mais apoio por meio de recursos, contratação de profissionais especializados e a formação continuada.

Em relação à formação continuada, a legislação compreende que transversalidade em todas as disciplinas é a melhor forma para se abordar esse tema, apesar de sua complexidade. Todavia, para que isso ocorra, as formações são essenciais para que os profissionais aprendam, discutam, criem, as formas mais adequadas de abordarem esse tema em suas atividades/aulas. De acordo com as diretoras das escolas municipais, existe formação continuada para os professores, sobretudo, a partir de parcerias feitas com a Itaipu e com o Sicredi. O município também oferece formações com o tema sobre a Educação Ambiental.

Já o Estado realiza formação continuada com temas pré-estabelecidos. Contudo, como não são temas que se vinculam com a realidade das escolas, as diretoras adaptam esses temas e fazem formações, com temáticas que estejam mais voltadas à necessidade que é detectada no momento, como por exemplo, a prevenção ao suicídio. A formação continuada nas escolas ocorre no início do ano, em julho e em outubro. A parceria com a Itaipu se tornou importante, pois ela é fomentadora de muitos cursos e fornece diversas outras formações para a equipe da Rede Escolar de Santa Tereza do Oeste. Segundo as diretoras, os professores de ciências e biologia têm formação em educação ambiental, em relação aos objetivos do desenvolvimento sustentável (ODS) e a Agenda 2030.

Apesar de não ter ocorrido entrevistas com os professores, ficou claro que, embora seja aplicado o princípio da transversalidade quanto à Educação Ambiental nas escolas estaduais, não são todos os professores que recebem formação para isso. Sendo assim, seria interessante que fosse pensado em formação continuada para todos os professores.

Em relação à categoria de análise família e comunidade, o Programa Nacional de Educação Ambiental (ProNEA), ao propor a reestruturação dos currículos escolares para a promoção da EA, indica a importância do desenvolvimento de projetos pedagógicos de pesquisas em todos os âmbitos, permitindo o envolvimento das comunidades. Buscando a construção do processo de socialização, propiciando que o aluno se torne um cidadão responsável e 
multiplicador de ações ecológicas e sustentáveis. Além disso, a proposição do Art. 225 na seção VI da Constituição Federal, pontua que a Educação Ambiental deve ocorrer em todos os níveis de ensino, permeando a conscientização pública sobre esses temas (BRASIL, 1988). Ou seja, a união e o diálogo entre escola/ estudantes com família e comunidade são uma ótima forma de promover a aprendizagem, construir conhecimentos e contribuir para o desenvolvimento de todos.

Segundo as diretoras das escolas municipais, poucas famílias participam das atividades nas/das escolas. A diretora da Escola Hélio Balarotti, esclareceu que é um "meio a meio". Têm aquelas, que se precisar, estão todos os dias na escola e têm aquelas que não aparecem. Situação que se torna preocupante, pois o sentido de pertença acaba sendo negligenciado, motivando ao aluno a sensação de abandono.

Quanto à participação da comunidade nos projetos escolares, foi enfatizado que "a comunidade é mais difícil de interagir. É até mais fácil a família do que, de certa forma, o setor da comunidade", palavras da Diretora da Escola Municipal Hélio Balarotti. A interação da comunidade ocorre quando são organizadas festas. E, também, quando são desenvolvidos projetos maiores como, por exemplo, o projeto da coleta seletiva.

Segundo a fala das diretoras, há muitos problemas com as famílias, motivados pelo fato de os pais não saberem mais educar os filhos. Pais de crianças de três anos falam "não sei mais o que fazer com meus filhos". A partir da avaliação das diretoras, a comunidade não tem trazido coisas boas para a escola. "Os pais não sabem mais dizer não aos filhos".

Assim como foi visto nas escolas municipais, nas escolas estaduais a participação das famílias também é restrita. Muitas só vão à escola por meio do Conselho Tutelar, conforme salientou a diretora SP, da Escola do Campo Artur Agostini, "muitos pais vêm somente na escola se o Conselho tutelar for chamar".

Em relação à comunidade, sua única participação é na feira de ciências. Não há interesse por parte dos pais e comunidade em trabalhar na Associação de Pais, Mestres e Funcionários (APMF) e no Conselho Escolar.

Na Escola Estadual do Campo de Santa Maria, a diretora VA afirma que a situação é um pouco melhor. Todavia, também enfrenta problemas similares. Ficou evidente o quanto há de negligência por parte das famílias no acompanhamento dos seus filhos nas atividades estudantis. Esses problemas enfrentados nas escolas parecem ter como possível forma de resolução a criação de projetos que é o tema da próxima categoria de análise.

Nas Diretrizes Curriculares Nacionais para Educação Ambiental (BRASIL, 2012), no que diz respeito à organização escolar, é definido no Art. 17 que: 
[...] considerando os saberes e os valores da sustentabilidade, a diversidade de manifestações da vida, os princípios e os objetivos estabelecidos, o planejamento curricular e a gestão da instituição de ensino devem promover $[\ldots]$, dentre outras atividades, projetos [...] que valorizem o sentido de pertencimento dos seres humanos à natureza, a diversidade dos seres vivos, as diferentes culturas locais, [...] inclusive desenvolvidas em espaços nos quais os estudantes se identifiquem como integrantes da natureza [...] (BRASIL, 2012, p. 6).

Os projetos transversais são capazes de orientar o conhecimento acumulado nas diversas disciplinas e saberes, entre educadores e educandos. Assim como são importantes como um meio de envolver família e comunidade, contribuindo para o desenvolvimento da sociedade como um todo.

Os projetos desenvolvidos nas escolas municipais contam com diversas parcerias. Dentre elas a Sicredi, a Itaipu Binacional, o Instituto Agronômico do Paraná (IAPAR), Empresa Paranaense de Assistência Técnica e Extensão Rural (EMATER) e a própria Secretaria do Meio Ambiente do município. Alguns temas de projetos desenvolvidos são: recuperação de nascentes, prevenção contra a dengue e a coleta seletiva.

Atualmente, na escola Levino Jorge Weidmann, está ocorrendo um projeto em parceria com a Sicredi, de educação financeira. Nesse projeto, a escola está arrecadando óleo usado para a fabricação de sabão. Esse sabão é comercializado e o dinheiro destinado para atividades realizadas com os estudantes, conforme excerto da diretora:

Os projetos estão ainda engatinhando. Um que eu espero que continue, em relação à educação ambiental, é a coleta do óleo. Para fazer sabão para o uso da escola, é revender para os pais, porque porque o óleo vai para o meio ambiente e é prejudicial. E no início eu pensava assim, que era pouco. Gente, nós estamos com tanto óleo lá, que vai dar tanto sabão. E vamos fazer junto um bazar de roupas, para incentivar às crianças no projeto de educação financeira. Eu achei que não ia ter participação das famílias. Gente, todo dia está chegando óleo, conforme apontado pela Diretora da Escola Municipal Levino Jorge Weidmann.

O sucesso desse projeto está ocorrendo devido à preocupação do impacto do óleo no meio ambiente e ao interesse das crianças, elas querem ver 
acontecer, querem compreender o real significado do óleo no meio ambiente e oferecer alternativas para isso.

No CMEI Mariano Otto, existe o projeto de horta e de brinquedos recicláveis. De acordo com sua coordenadora, no "Projeto com os brinquedos recicláveis, os pais tinham que produzir o brinquedo com o filho em casa. Tem pai que fez avião que tem luz e tudo. Teve pai mais empolgado que a criança”. Esse projeto trouxe pontos positivos, pois aproximou os pais das crianças e a família da escola.

No CMEI Natalino Redivo, de acordo com sua coordenadora, está sendo desenvolvido o projeto de incentivo à leitura, da maleta viajante, com apoio do Sicredi. As crianças levam o livro para casa, para a leitura ser feita junto com os pais. Além disso, é solicitado o resgate de histórias antigas, a serem compartilhadas na escola, despertando o interesse das crianças. Em 2014 ocorreu também o projeto de coleta de pilhas e baterias.

Na Escola Municipal Hélio Balarotti, há alguns anos teve o projeto de horta e compostagem. Todavia, algumas parcerias não deram certo e os professores envolvidos ficaram desmotivados. O Projeto de Educação Financeira também está sendo executado nesse colégio e tem estimulado os estudantes a estudarem mais. Há um tempo desenvolveram o projeto da coleta seletiva. Como o município não tem coleta seletiva, a temática fez muito sucesso. Mas, ocorria que em sala ensinavam as crianças a separar e depois vinha o caminhão do município e misturava tudo. Isso foi desmotivador para estudantes e professores.

Em relação à disposição dos professores para trabalharem com os projetos nas escolas, "nessa parte, tem alguns que são muito parceiros, que adoram essa metodologia, mas são poucos. A coordenação e a direção têm sempre que estar acompanhando de perto para poder sair", palavras da diretora da Escola Levino Jorge Weidmann. A dificuldade ocorre, pois, os professores ficam preocupados com os conteúdos que precisam lecionar. Outra questão geradora de problemas para a continuidade dos projetos, é a constante troca de professores.

A Escola Estadual Santa Tereza desenvolveu o Projeto Mais Educação, com recursos federais, com o intuito de construir uma horta e uma cisterna. Nesse projeto ocorreram várias parcerias, a Secretaria do Meio Ambiente ajudou na reconstrução da horta e na captação de água da chuva, mas esse também passou por um período de desativação. Entretanto, novas parcerias, tais como com a Secretaria de Agricultura, alguns professores de Ciências e uns grupos de estudantes, permitiram que o projeto fosse reativado. Isso gerou nova motivação e conscientização quanto à alimentação saudável e importância da produção orgânica.

Outro projeto importante que vem sendo desenvolvido nas escolas estaduais é o despertando vocações. Ele surgiu a partir da parceria com uma 
empresa privada, a Cool Seed (empresa de construção de silos de secagem de grãos). Onde o dono da empresa, faz um resgate da sua história, conta as dificuldades enfrentadas, a pobreza e a superação econômica por meio da invenção dos primeiros equipamentos. $\mathrm{O} 2^{\circ}$ e $3^{\circ}$ ano do ensino médio realizam visitas à fábrica, à UNIPAR e ao SENAC, com o intuito de despertar a vontade de continuar com os estudos. Com isso, aproveitam para a aplicação de testes vocacionais. Além disso, são feitas palestras com os temas cidadania, prevenção das drogas, entre outros. E há o projeto jovem aprendiz que emprega jovens recém-formados no próprio município.

Outro projeto existente é o sobre Justiça Restaurativa. Em parceria com o Núcleo de Educação. Trabalha com o respeito, amor e perdão. Busca conquistar a confiança para que os estudantes falem sobre os seus problemas com o intuito de gerar uma cura emocional. De acordo com as diretoras, foi percebida uma mudança muito grande nos estudantes?

O que foi possível perceber é a potencialidade que o trabalho com os projetos apresenta, justamente, num dos maiores problemas que as escolas enfrentam - a relação com a família e comunidade. Os projetos descritos pelas diretoras demonstram que tiveram sucesso nessa parceria - familiares e comunidade. Nesse sentido, percebe-se a importância de se investir nesses processos, pois mostram-se como um meio profícuo de avançar nas relações familiares, com a comunidade e desenvolvem o aprendizado das crianças e jovens.

Por fim, o tema da Alimentação Saudável, vinculado ao PNAE e ao trabalho da Agricultura Familiar, envolve vários assuntos muito ricos paras as reflexões, discussões e trabalhos com a Educação Ambiental. Como um tema interdisciplinar, aborda problemas complexos, os quais podem ser explorados em diferentes disciplinas. Sendo assim, os estudantes, ao mesmo tempo em que podem aprender diferentes conteúdos, que estão presentes nos currículos das disciplinas, podem contribuir para a reflexão de suas próprias realidades no município e região, bem como pensar em projetos e meios para resolver os desafios encontrados e/ou, fortalecer potencialidades identificadas.

Em Santa Tereza do Oeste, a prefeitura mantém o compromisso da aquisição de $30 \%$ da alimentação escolar da agricultura familiar, prevista pela Lei 11.947/2009 (BRASIL, 2009). Grande parte desses alimentos é oriunda dos

\footnotetext{
${ }^{7}$ Outros projetos realizados nas escolas estaduais são: agrinho, feira cultural, intersalas (jogos), trabalho com horta e compostagem, trabalho com reciclagem, alimentação saudável. Esse último é realizado a partir da discussão da alimentação escolar, que é oriunda da agricultura familiar do município, no caso, de assentados da reforma agrária. Nesse projeto, os alunos realizaram visitas ao Assentamento Sepé Tiaraju, onde puderam conhecer como a produção dos alimentos orgânicos é realizada. Além disso, puderam visitar sítios modelos de sustentabilidade, como a chácara do viceprefeito Ivonir e o Instituto Pedra da Mata.
} 
assentamentos de reforma agrária do município, Olga Benário e Sepé Tiaraju, que preserva a preocupação em produzir alimentos orgânicos. A prefeitura estuda a possibilidade de aumentar esse percentual de compra dos alimentos da agricultura familiar. Temática que passa a ser discorrido em relação às escolas de Santa Tereza do Oeste.

As diretoras das escolas municipais afirmaram que, como as crianças são muito pequenas, estes temas ainda não são trabalhados. Mas as escolas adquirem produtos do PNAE, orgânicos e as merendeiras passaram por vários cursos, inclusive pela Itaipu, para oferecer comidas com aparência e sabor que pudessem ser valorizados pelas crianças. De acordo com a professora da Escola Levino Jorge Weidmann, na escola a alimentação saudável é valorizada, pois as merendeiras são preparadas e as crianças adoram as comidas. Sua afirmação permite observar que um alimento quando feito com conhecimento de seus nutrientes, pode fazer a diferença no prato dos estudantes.

Embora, muitas vezes não seja aprofundado o tema da alimentação escolar fazendo o vínculo com a produção orgânica da agricultura familiar do município, percebe-se que o tema da qualidade da alimentação é algo que está presente nas escolas. Ou seja, a preocupação com a alimentação saudável existe. A manutenção, das hortas e dos projetos permitiu a percepção da importância de que estes tipos de alimentos podem se tornar de larga escala, para a alimentação dos alunos.

Apesar de todas as escolas municipais receberem alimentos oriundos da agricultura familiar do município de Santa Tereza do Oeste, mais especificamente, alimentos orgânicos de assentamentos, as diretoras afirmaram que não conhecem os assentamentos, nem os trabalhos realizados por eles. Que nunca foi feito nenhuma excursão para levar as crianças para conhecerem essas experiências. Observa-se que existe um imenso potencial ainda inexplorado por essas escolas: conhecer a história de seu próprio município; como esses assentamentos foram formados, bem como a forma que produzem os alimentos. Poder-se-ia estudar as diferenças de produção da agricultura familiar com o Agronegócio. Outras situações a serem analisadas se faz com relação a diversidade/qualidade da produção, assim como o processo para que esses alimentos cheguem até a escola. Percebe-se que muitas situações podem ser repassadas em relação ao agronegócio e os impactos que a monocultura pode causar ao meio ambiente. Mesmo que se trate de crianças, excursões para conhecer o espaço de produção dessas famílias assentadas é uma ótima forma de sensibilização. Além do contato com a terra, saber de onde vêm os alimentos é uma importante forma de mostrar às crianças a realidade que as cerca.

As escolas estaduais também recebem alimentos orgânicos oriundos da agricultura familiar, vindos dos assentamentos Sepé Tiaraju e Olga Benário. Os 
cardápios são feitos nas escolas (o Estado não tem nutricionista por núcleo e muito menos nas escolas). Os professores conhecem a história desses assentamentos e trabalham isso com os alunos em sala de aula, pois visitas já foram feitas ao assentamento Sepé Tiaraju. Os alunos também foram conhecer a chácara do vice-prefeito, porque sua propriedade é um exemplo de sustentabilidade, com produção sem agrotóxicos e adubos químicos, com produção de frutas, hortaliças, frango e experiências com um biodigestor. Também levaram um grupo de alunos ao Instituto Pedra da Mata que foca em suas práticas à educação e a sustentabilidade. O Instituto diante de suas atividades relacionadas a novos modelos de habitação, produção de alimentos, saneamento, energias alternativas, educação e trabalho centrados na vida, promovem a reflexão sobre o paradigma vigente na sociedade de consumo, criando condições para o questionamento e a criação de novas formas de existir, mais satisfatórias e sustentáveis.

Segundo a diretora da escola Santa Tereza "toda a visita externa em propriedades referenciais provoca nos alunos e professores uma reflexão sobre comportamento". E, antes das visitas, discussões e análises sobre a proposta são realizadas em sala de aula. Tendo isso em vista, observou-se que as escolas estaduais já perceberam o potencial que o município apresenta e trabalham sobre isso com seus estudantes.

\section{CONCLUSÃO}

Buscou-se por meio dessa pesquisa, no município de Santa Tereza do Oeste, compreender como a Educação Ambiental vem sendo trabalhada, de maneira que contribua para o desenvolvimento sustentável do município.

Foi constatado que as escolas municipais têm cumprido de forma parcial a legislação sobre EA, pois não atendem a determinação de que a Educação Ambiental seja trabalhada de forma transversal em todas as disciplinas e não apenas em uma única. Situação que gera outros problemas enfrentados pela rede municipal como, por exemplo, o desinteresse dos professores em trabalhar com esse assunto. Por outro lado, observou-se que a rede municipal segue as Leis quanto à preocupação de trabalhar com a interdisciplinaridade, projetos que envolvam a família e comunidade, a construção e disseminação de princípios e valores e a formação continuada de seus profissionais. Observou-se que existe um potencial no município que poderia ser mais bem aproveitado pelas escolas municipais em relação às atividades de Educação Ambiental, mas que o apoio do governo municipal se torna fundamental. Assim como o papel das famílias e comunidade, para que valorizem e apoiem os trabalhos desses profissionais.

Em relação às escolas estaduais, estas têm seguido as normativas. Contudo, assim como as municipais, elas poderiam aproveitar melhor o 
trabalho com a interdisciplinaridade e as contradições expostas no município (pela secretaria de meio ambiente e comunidade), para a formação de sujeitos críticos. Da mesma forma, esses profissionais da educação precisam do apoio dos governos municipais e estaduais, seja na contratação de profissionais especializados ou por meio de recursos ou ainda em formações continuadas, para que a EA seja fortalecida.

Ficou evidenciado que a Educação Ambiental tem contribuído para o desenvolvimento do município em relação à conscientização de questões como coleta seletiva, limpeza dos espaços urbanos e alimentação saudável. Todavia, ficou claro que existe um potencial ainda pouco explorado, como a contradição entre a agricultura familiar e o agronegócio, discussões sobre saneamento básico, sobre como a sociedade tem gerado a individualização excessiva dos sujeitos, perdendo a capacidade de se organizar e reivindicar mudanças, focando apenas em seus problemas pessoais sem conseguir perceber as causas sociais dos mesmos, levando, inclusive a problemas psicológicos.

Indica-se, com isso, as sugestões acima levantadas, como temas à futuros trabalhos e projetos a serem desenvolvidos tendo como alicerce a EA. A demonstração das parcerias entre as escolas e o governo municipal, pode, porém, ser uma lacuna de distanciamento com pesquisas que possam ocorrer em outros municípios. Assim como, com a comunidade que traz diferentes perspectivas dos problemas enfrentados nos municípios, bem como, alternativas e sugestões para enfrentá-los e resolvê-los. Como exemplos positivos à essa temática, podem ser citados os assentamentos de reforma agrária que trabalham com a agroecologia e o Instituto Pedra da Mata que apresenta diferentes experiências de sustentabilidade e oferece formações e oficinas diversas.

\section{AGRADECIMENTOS}

Às diretoras das escolas e secretaria da educação do município pelo apoio e tempo dedicados à coleta de dados por meio dos grupos focais e discussão sobre a temática. A fim de preservar suas identidades, por ética e respeito, os nomes das diretoras e secretárias entrevistadas foram suprimidos.

\section{REFERÊNCIAS}

AHLERT, A. A Eticidade da educação: o discurso de uma práxis solidária/ universal. ed. 2. Ijuí: Unijuí, 2003.

BRASIL. Constituição (1988). Constituição da República Federativa do

Brasil. Brasília, DF: Senado Federal, 1988. 
. Lei n ${ }^{\circ}$ 9.394, de 20 de dezembro de 1996. Estabelece as Diretrizes e Bases da Educação Nacional. Diário Oficial [da] República Federativa do Brasil. Brasília, DF, v. 134, n. 248. Seção 1, p. 27834-27841.1996.

. Lei da Política Nacional de Educação Ambiental, Lei n ${ }^{\circ} 9.795$, de 27 de abril de 1999. Brasília: Senado Federal.1999.

. Ministério do Meio Ambiente (MMA). Identidades da Educação Ambiental Brasileira. Philippe Pomier Layrargues (coord.) Brasília. 2004.

. Presidência da República. Lei n. ${ }^{\circ} 11.947$ de 16 de junho de 2009. Dispõe sobre o Atendimento da alimentação escolar e do Programa Dinheiro Direto na Escola aos alunos da educação básica. 2009.

. Ministério da Educação. Conselho Nacional de Educação. Conselho Pleno. Resolução n ${ }^{\circ}$ 2. Diretrizes Curriculares Nacionais para a Educação Ambiental. 2012.

. Lei n ${ }^{\circ}$ 13.146. Lei Brasileira de Inclusão da Pessoa com Deficiência. 2015. Disponível em: http://www.planalto.gov.br/ccivil_03/_ato20152018/2015/lei/113146.htm. Acesso em: 08 jun. 2017.

FANTINATO, M. Método de Pesquisa. 2015. Disponível em: http://each. uspnet.usp.br/sarajane/wp-content/uploads/2015/09/Métodos-de-Pesquisa.pdf. Acesso em: 01 jun. 2017.

FRÓES, C. Q.; MILANEZI, C. H. S.; BOGARIM, E. P. A. Percepção Ambiental do Campus Universitário na Faculdade de Ciências Biológicas e Ambientais da UFGD. Instituto Brasileiro de Estudos Ambientais (IBEAS). 2011.

LEFF, E. Epistemologia ambiental. São Paulo: Cortez, 2001.

LÜDKE, M. Pesquisa em educação: abordagens qualitativas. São Paulo: EPU, 1986.

MARCONI, M. A; LAKATOS, E. M. Fundamentos da metodologia científica. 8. ed. São Paulo: Atlas, 2017.

PARANÁ. Lei Complementar n 37. Dispõe sobre o Regime Diferenciado de Trabalho (RDT). 1987. 
Conselho Estadual de Educação. Normas Estaduais para a Educação Ambiental no Sistema Estadual de Ensino do Paraná, com fundamento na Lei Estadual n 17.505. 2013.

SANTA TEREZA DO OESTE. Plano Diretor de Santa Tereza do Oeste: diretrizes para o desenvolvimento do município. Santa Tereza do Oeste: Prefeitura de Santa Tereza do Oeste, 2015.

SEVERINO, A. J. Metodologia do trabalho científico. 23. ed. São Paulo: Cortez, 2007.

VAUGHN, S. et al. Focus group interviews in education and psychology. Thousand Oaks, CA: Sage Publications, 1996. 